\title{
A study to assess the patient satisfaction regarding treatment and care in emergency department of New Delhi hospital, India
}

\begin{abstract}
Emergency departments overcrowding, inadequate nurse patient ratio, wait for start of necessary treatment and lack of communication with family members may lower perceived quality of the patient satisfaction.
\end{abstract}

Aims: To assess the patient satisfaction in terms of nursing care and treatment in emergency department.

Material and Methods: The cross sectional descriptive survey was carried among randomly selected 150 patients admitted for $>24 \mathrm{hrs}$, in three units of emergency department (Medical emergency, surgical emergency and Trauma emergency) during February to March 2017. Patient satisfaction questionnaire containing 20 items related to admission process, physical environment, ongoing treatment and discharge information was used as tool for data collection. Subjects were interviewed for data collection.

Results: The overall quality of care was reported as satisfied by $55 \%$ subjects. In further analyzing the components of patient satisfaction, $51 \%$ subjects were satisfied for efficiency of admission process and $47 \%$ with examination performed by doctor. Whereas dissatisfaction was reported in case of physical cleanliness $(59 \%)$, high noise level $(53 \%)$ and lack of potable water and clean toilets by $58 \%$ subjects. $61 \%$ subjects were satisfied with well explanation of disease condition and $49 \%$ with availability of doctors and nurses in emergency. At the same time, subjects reported not satisfaction with components like long waiting times (53\%), clinical care $(47 \%)$, maintaining privacy $(41 \%)$ and communication $(55 \%)$. The duration of hospital stay and type of emergency unit had significant association with patients' level of satisfaction at $\mathrm{p}<0.05$.

Conclusions: Overall higher numbers of subjects were satisfied with admission process, examination by doctors and explanation of disease condition but unsatisfied with services like long waiting time, communication and clinical care in emergency department.

Keywords: patient satisfaction, treatment and care
Volume 5 Issue 6 - 2018

\section{Seema Sachdeva, Harmanpreet Kaur \\ Department of College of Nursing, All India Institute of Medical Sciences, India}

Correspondence: Seema Sachdeva, Faculty in nursing, All India Institute of Medical sciences, Department of College of Nursing, AllMS, New Delhi, India, Tel 918588869012 ,

Emailsachdevaiims@gmail.com

Received: July 12, 2018 | Published: November 22, 2018

\section{Introduction}

Health care sectors have an extremely competitive environment and patient satisfaction is one of the important factors which determine the success of health care facility. ${ }^{1}$ The real challenge is not getting ready with mere requirements, but also in delivering good quality services. ${ }^{2}$. Patient's satisfaction with nursing care is considered the major predictive factor of overall satisfaction and hence it can be further utilized as an important tool to improve the quality of services. Improved satisfaction in emergency department is likely to have a significant impact on the public view of hospital. Satisfied patients may be more compliant with their medical regimens which further promote health and well-being parts. ${ }^{3}$

Consumer satisfaction regarding medical care organization is important in the provision of services to patients. There is paucity of studies in Indian scenario on patient satisfaction especially in emergency setting. Hence to evaluate quality of care and treatment, patient satisfaction was explored in emergency department of AIIMS,
New Delhi. The patient's satisfaction was assessed in terms of two objectives:

1) To assess the patient satisfaction in terms of care and treatment in emergency department.

2) To find the association of patient satisfaction with selected variables.

\section{Materials and methods}

Across sectional survey was carried out among 150 patients admitted in emergency department (Medical emergency, surgical emergency and trauma emergency unit) for $>24 \mathrm{hrs}$ of hospital admission in All India Institute of Medical sciences, New Delhi, India, during February and March 2017. The simple random sampling technique was used to select study samples from all 3 units of emergency. The patients who were conscious, age $>18$ years and were able to respond to were taken in inclusion criteria. The exclusion criteria were red triaged patients, patients with any kind of mental disorders or under the effects of 
sedatives/hypnotics. A pre structured questionnaire was used as tool which included first part as socio demographic and Clinical variables like age, gender, education, hospital duration, type of admission and emergency unit. The second part had 'Patient Satisfaction Questionnaire' with 20 Items related to Admission process, Physical environment, ongoing treatment and transfer or discharge/information. Admission process had items related to waiting time, examination by doctor and efficiency of admission process. The Physical environment had items for environmental hygiene, noise level, room temperature, potable water and clean toilets. The ongoing treatment had statement pertinent to explanation of disease condition, clinical care by nurses, communication; maintain privacy, taking consent, showing prompt response in emergency and spending time with patient. There was single item for discharge/ transfer process. The responses were marked on three point likert scale ranging from 'Satisfied, Not Certain and Not Satisfied'. The validity and reliability of the tool was established. The ethical permission was obtained from Institute ethics Committee. Data was collected by interviewing the subjects after obtaining the written informed consent from them.

Data was entered in MS excel and analyzed using Strata 12. Descriptive statistics was used to analyze the mean and frequency of demographic data and responses of subjects for patient's satisfaction. Inferential statistics was used to find the association of patient satisfaction with selected variables. Level of significance was kept at $\mathrm{p}<0.05$.

\section{Results}

A total of 150 subjects from emergency department were included in this study. Out of 150 subjects, majority were male (64\%). The mean age group was 33.2 years (Range 18-68 years). Most of the subjects were married $(73 \%)$, educated to secondary standard (48\%) and nearly half of the subjects ( $42 \%)$ belonged to low income group with total income $<$ Rs 5000/ month. In medical emergency, majority of subjects had respiratory system disorder (46\%) followed by cardiovascular $(28 \%)$ and hematological disorders $(12 \%)$. While in surgical emergency majority had gastro intestinal disorders $(69 \%)$ and in trauma emergency $71 \%$ subjects were road traffic accidents victims. Regarding hospital stay, $66 \%$ subjects had stay of $48-72 \mathrm{hrs}$

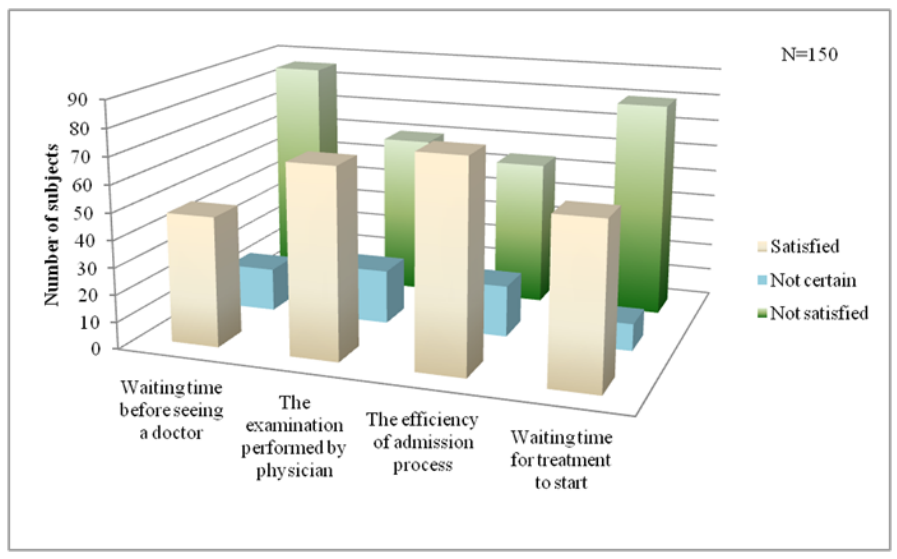

Figure I Patient satisfaction regarding admission process. in medical emergency while majority had stay of $24-48 \mathrm{hrs}$ both in surgical emergency (64\%) and trauma emergency (74\%). In type of admission, $76 \%$ subjects were admitted to emergency unit as a new admission while $24 \%$ were follow up patients needed emergency treatment.

In regard to patient satisfaction for admission process in emergency department, majority of the subjects $(n=77,51 \%)$ were satisfied with efficiency of online admission process and examination performed by physician $(n=70,47 \%)$. While majority of patients reported non satisfaction for waiting time to be examined by doctor $(n=86,57 \%)$ and waiting time for start of treatment in emergency $(n=80,53 \%)$ as shown in Figure 1.

In Physical environment (Figure 2), majority of the subjects were not satisfied with physical cleanliness $(\mathrm{n}=88,59 \%)$, high noise level $(n=79,53 \%)$, toilet hygiene and potable water facilities $(n=87$, $58 \%$ ). On the other hand the most of the subjects were satisfied with adequate ventilation, illumination $(\mathrm{n}=71,47 \%)$ and room temperature $(\mathrm{n}=89,59 \%)$.

Data in Table 1 reveals the satisfaction with regard to ongoing treatment in emergency department. The most of subjects showed satisfaction with well explanation of disease condition by doctor $(\mathrm{n}=92,61 \%)$, availability of doctors and nurses for treatment $(\mathrm{n}=73$, $49 \%)$ and overall quality of care $(n=71,47 \%)$ provided by emergency health care staff. On the other hand, dissatisfaction was expressed with the aspects like taking informed consent before any procedure $(n=71$, $47 \%$ ), maintaining their privacy ( $\mathrm{n}=62,41 \%)$, showing promptness to emergency situation $(n=73,49 \%)$, communication $(n=82,55 \%)$ and clinical care by nurses $(\mathrm{n}=70,47 \%)$.

In discharge or transfer process, nearly half of the subjects $(n=65,45 \%)$ expressed uncertain level of satisfaction as no proper information had been provided regarding area of transfer, further treatment or follow up information.

For the association of patient's satisfaction with demographic and clinical variables using ANOVA test with $p<0.05$ as significant, revealed the significant association of patient satisfaction with education $(\mathrm{p}=0.03)$, duration of hospital stay $(\mathrm{p}=0.029)$, and type of emergency unit ( $\mathrm{p}$ value 0.003 ).

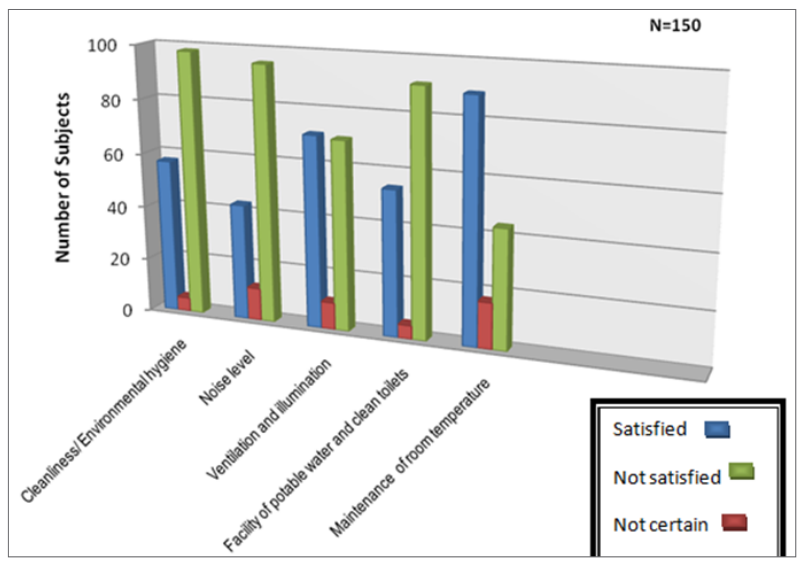

Figure 2 Patients satisfaction with physical environment. 
Table I Frequency distribution of subjects' satisfaction level with ongoing treatment and investigations $N=\mid 50$

\begin{tabular}{|c|c|c|c|}
\hline Items & Satisfied & Not certain & Not satisfied \\
\hline Explanation of disease condition & 92 & 15 & 43 \\
\hline Explanation of procedure, related investigation, its cost and treatment & 51 & 38 & 61 \\
\hline Clinical care by nurses & 66 & 14 & 70 \\
\hline Availability of doctors and nurses for my treatment and care & 73 & 9 & 68 \\
\hline Promptness of the staff in responding to emergency & 60 & 17 & 73 \\
\hline Time spent by treating staff $r /$ to my treatment, care and recommendations & 60 & II & 79 \\
\hline Informed consent before any procedure/ investigation & 25 & 54 & 71 \\
\hline Maintaining privacy & 41 & 47 & 62 \\
\hline Communications by Doctors/ nurses and other Para medical staff & 41 & 27 & 82 \\
\hline Overall quality of care provided by emergency health care staff & 71 & 33 & 46 \\
\hline
\end{tabular}

\section{Discussion}

Patient satisfaction affects clinical outcomes, patient retention, and patient-centered delivery of quality health care. ${ }^{3}$ The present study was done in three units of emergency department (medical, surgical and trauma unit) on 150 patients using random sampling method. The study focused on patient satisfaction for treatment and care in emergency department which was further sub grouped into satisfaction for admission process, physical environment, ongoing treatment and discharge process. For admission process, majority of the subjects reported their satisfaction for computerized admission process $(51 \%)$ and examination done by doctor $(47 \%)$ but also reported not satisfaction for waiting time for examination (57\%) and delay in start of treatment (53\%) (Figure 1). A similar findings were suggested in a study where overall satisfaction was more strongly associated with the perception of the physician wait interval $(r=0.37$; $\mathrm{p}=0.00001){ }^{4}$ The results were also comparable with the study done by Anderson et al; ${ }^{5}$ which suggested that the combination of long wait times and short visit times by senior doctors produced the lowest level of patients' satisfaction in acute care units. ${ }^{5}$

Regarding patients satisfaction for physical environment, majority of the subjects were not satisfied with poor physical cleanliness $(59 \%)$, lack of toilet hygiene and clean water (Figure 2). This is in line with previous research study conducted in Cardiothoacic centre, AIIMS, New Delhi, India, which reported that only 35\% subjects were satisfied with toilet and environmental cleanliness and 32\% with diet services. ${ }^{6}$

In present study, majority of the subjects reported satisfaction with availability of doctors and nurses in emergency department (49\%). This was contrary to the findings of previous study performed in teaching hospital in India which highlighted the decrease availability of health care staff especially in evening and night shift. ${ }^{7}$ Continuing with ongoing treatment, most of the subjects reported dissatisfaction with procedures like maintaining privacy ( $41 \%)$, showing promptness to any emergency situation and communication by doctors and nurses with patients $(51 \%)$. These results are in contrast with a study done in district hospital in Iran which reported that 94\% patients liked nursing practice of keeping privacy of patients. Whereas the same study reported that $84 \%$ patients had negative experiences as they observed nurses were not attentive to their needs, particularly at night. ${ }^{8}$ In present study, $47 \%$ of the subjects were not satisfied with clinical care by nurses. Whereas another study conducted on patient satisfaction with nursing care at national hospital in Sri lanka reported that $81.8 \%$ subjects were satisfied with interpersonal care, $89.7 \%$ with efficiency and competency of nursing staff. ${ }^{9}$ However another study in contrast on patient satisfaction regarding nursing care revealed that $50 \%$ of the patients reported insufficient time spent by nursing staff, ${ }^{10}$ which is very near to results obtained in the present research, in which $52 \%$ subjects stated that the nursing staff had no time to listen to their needs. This can be attributed to high workload and frequent turnover of patients in emergency unit.

The result of this study showed that the majority of the subjects $(45 \%)$ were uncertain regarding discharge/transfer process. The findings goes in line with another study reported by Worku $\mathrm{M}^{11}$ where $43.6 \%$ patients reported that nurses did not give sufficient instructions, where to come for follow up and what to expect at home for the patients discharged from emergency. ${ }^{11}$

Regarding association of patient satisfaction with demographic and clinical variables, a significant association was found of patients satisfaction with education, hospital duration and type of emergency unit with $\mathrm{p}<0.05$. Satisfaction was found more in patients admitted to trauma unit (77\%) than medical and surgical emergency $(24 \%)$. The increase in hospital stay for $>24 \mathrm{hrs}$ improved satisfaction among subjects which could be attributed to adjusting in hospital set up and start of patient treatment. The results are comparable to the study done in India, where literacy level $(\mathrm{p}<0.002)$ and hospital stay $(\mathrm{p}<0.001)$ had significant association with patient's satisfaction. ${ }^{6}$

\section{Conclusion}

The majority of subjects were satisfied with number of emergency services like computerized admission process, availability of the health care staff, examination done in emergency and well explanation of disease condition. On the other hand, the majority of the subjects were not satisfied with the services like waiting time, informed consent; maintain privacy, poor communication, and delay in showing promptness to emergency and clinical care by nurses. Patients satisfaction had a significant association with hospital stay and the literacy level of the subjects. 


\section{Recommendations}

The present study recommends the responses of subjects to be used as a method to improve the quality of services provided to clients and develop the guidelines for emergency health care staff to give safe competent care to their clients.

\section{Acknowledgments}

We give our sincere thanks to our experts for validation of tool (Dr. Parveen Aggarwal, Dr. Sanjeev Bhoi, Dr Akshay Kumar, (Faculty, Department of emergency medicine) and Ms. Suman (Deputy Nursing Superintendent, Emergency ward) and our study subjects for their cooperation.

\section{Conflicts of interest}

Author declares that there is none of conflicts.

\section{References}

1. You L, Aiken LH, Sloane DM, et al. Hospital nursing, care quality, and patient satisfaction: cross-sectional surveys of nurses and patients in hospitals in China and Europe. Int J Nurs Stud. 2013;50(2):154-161.

2. Cleary PD, McNeil BJ. Patient satisfaction as an indicator of quality care. Inq J Med Care Organ Provis Financ. 1988;25(1):25-36.

3. Davis BA, Duffy E. Patient satisfaction with nursing care in a rural and an urban emergency department. Aust J Rural Health. 1999;7(2):97-103.
4. Parra Hidalgo P, Bermejo Alegría RM, Más Castillo A, et al. [Factors related to patient satisfaction with hospital emergency services]. Gac Sanit. 2012;26(2):159-165.

5. Anderson RT, Weisman CS, Scholle SH, et al. Evaluation of the quality of care in the clinical care centers of the National Centers of Excellence in Women's Health. Womens Health Issues Off Publ Jacobs Inst Womens Health. 2002;12(6):309-326.

6. Mishra PH, Gupta S. Study of patient satisfaction in a surgical unit of a tertiary care teaching hospital. J Clin Orthop Trauma. 2012;3(1):43-47.

7. Samina M, GJ Q, Tabish S, et al. Patient's Perception of Nursing Care at a Large Teaching Hospital in India. Int J Health Sci. 2008;2(2):92-100.

8. Khan MH, Hassan R, Anwar S, et al. Patient Satisfaction with Nursing Care. Rawal Med J. 2007;32(1):28-30.

9. Senarath U, Gunawardena NS, Sebastiampillai B, et al. Patient satisfaction with nursing care and related hospital services at the National Hospital of Sri Lanka. Leadersh Health Serv. 2013;26(1):63-77.

10. Bernal MMY, Rocha RMR. Level of Satisfaction of the Beneficiaries with the Nursing Care of a Social Security Institution. Nursing \& Care Open Access Journal. 2017;4(1):351-353.

11. Worku M, Loha E. Assessment of client satisfaction on emergency department services in Hawassa University Referral Hospital, Hawassa, Southern Ethiopia. BMC Emerg Med. 2017;17(1):21. 